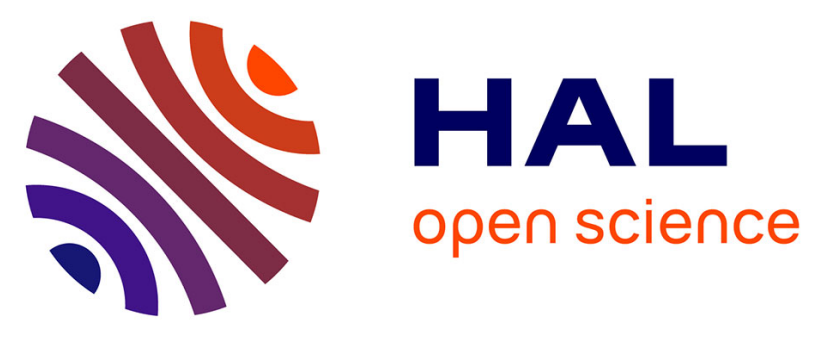

\title{
Primary Focal Dystonia: Evidence for Distinct Neuropsychiatric and Personality Profiles
}

\author{
Rebekka Lencer, Susanne Steinlechner, Jessica Stahlberg, Hilka Rehling, \\ Michael Orth, Tobias Baeumer, Hans-Juergen Rumpf, Christian Meyer, \\ Christine Klein, Alexander Muenchau, et al.
}

\section{To cite this version:}

Rebekka Lencer, Susanne Steinlechner, Jessica Stahlberg, Hilka Rehling, Michael Orth, et al.. Primary Focal Dystonia: Evidence for Distinct Neuropsychiatric and Personality Profiles. Journal of Neurology, Neurosurgery and Psychiatry, 2009, 80 (10), pp.1176. 10.1136/jnnp.2008.170191 • hal-00552757

\section{HAL Id: hal-00552757 https://hal.science/hal-00552757}

Submitted on 6 Jan 2011

HAL is a multi-disciplinary open access archive for the deposit and dissemination of scientific research documents, whether they are published or not. The documents may come from teaching and research institutions in France or abroad, or from public or private research centers.
L'archive ouverte pluridisciplinaire HAL, est destinée au dépôt et à la diffusion de documents scientifiques de niveau recherche, publiés ou non, émanant des établissements d'enseignement et de recherche français ou étrangers, des laboratoires publics ou privés. 


\section{Primary Focal Dystonia: Evidence for Distinct Neuropsychiatric and Personality Profiles}

Rebekka Lencer ${ }^{1 *}, M D$, Susanne Steinlechner ${ }^{1 *}, M D$, Jessica Stahlberg ${ }^{1}, M D$, Hilka Rehling ${ }^{1}$, MD, Michael Orth ${ }^{2}$, MD PhD, Tobias Baeumer ${ }^{2}$, MD, Hans-Juergen Rumpf $^{1}, \mathrm{PhD}$, Christian Meyer ${ }^{4}, \mathrm{PhD}$, Christine Klein ${ }^{3}, \mathrm{MD}$, Alexander Muenchau ${ }^{2}$, MD, Johann Hagenah ${ }^{3}$, MD

${ }^{1}$ Departments of Psychiatry and Psychotherapy, and ${ }^{3}$ Neurology, University of Luebeck, Luebeck, Germany

${ }^{2}$ Department of Neurology, University of Hamburg, Hamburg, Germany ${ }^{4}$ Institute of Epidemiology and Social Medicine, Ernst-Moritz Arndt University, Greifswald, Germany

Corresponding author:

Rebekka Lencer, MD

Department of Psychiatry and Psychotherapy, University of Luebeck

Ratzeburger Allee 160, 23538 Luebeck, Germany

Tel: +49-451-500-2444, Fax: +49-451-500-4957

e-mail: rebekka.lencer@psychiatrie.uk-sh.de

Keywords: Primary Focal Dystonia, Psychiatric Disorders, Personality Disorder, Personality Traits, Population-based Prevalence Rates

* Drs Lencer and Steinlechner contributed equally to this study.

Statistical analysis was conducted by Hans-Juergen Rumpf, PhD. 
Disclosure: The authors report no conflicts of interest.

Exclusive License: The Corresponding Author has the right to grant on behalf of all authors and does grant on behalf of all authors, an exclusive licence (or nonexclusive for government employees) on a worldwide basis to the BMJ Publishing Group Ltd and its Licensees to permit this article (if accepted) to be published in JNNP and any other BMJPGL products to exploit all subsidiary rights, as set out in our licence.

Manuscript: 87 characters for title; 1672 words plus abstract of 202 words 


\section{Abstract}

Background: Primary focal dystonia (PFD) is characterized by motor symptoms. Frequent co-occurrence of abnormal mental conditions has been mentioned for decades but is less well defined. We evaluated prevalence rates of psychiatric disorders, personality disorders and traits in a large cohort of PFD patients.

Methods: Prevalence rates of clinical psychiatric diagnoses in 86 PFD patients were compared to a population-based sample $(\mathrm{N}=3943)$ using a multiple regression approach. Furthermore, participants were evaluated for personality disorders with the Five Factor Personality Inventory.

Results: Lifetime prevalence for any psychiatric or personality disorder was $70.9 \%$. More specifically, axis I disorders occurred at a 4.5-fold increased chance. Highest odds ratios were found for social phobia (OR 21.6), agoraphobia (OR 16.7) and panic disorder (OR 11.5). We further found an increased prevalence rate of $32.6 \%$ for anxious personality disorders comprising obsessive-compulsive $(22.1 \%)$ and avoidant personality disorders (16.3\%). Except for social phobia, psychiatric disorders manifested prior to the occurrence of dystonia symptoms. In the self-rating of personality traits, PFD patients demonstrated pronounced agreeableness, conscientiousness, and reduced openness.

Conclusions: Patients with PFD show distinct neuropsychiatric and personality profiles of the anxiety spectrum. PFD should therefore be viewed as a neuropsychiatric disorder rather than a pure movement disorder.

\section{Abbreviations:}

M-CIDI = Munich Composite International Diagnostic Interview DSM = Diagnostic and Statistical Manual of Mental Disorders 
PFD $=$ Primary Focal Dystonia

SCID = Structured Clinical Interview for DSM-IV

SGCE $=$ Epsilon Sarcoglycan Gene 


\section{Introduction:}

Primary focal dystonia (PFD) is typically classified as a movement disorder, although several studies suggest that psychiatric conditions such as social phobia,[1,2] major depressive disorder,[3] and obsessive-compulsive symptoms [4] occur at increased rates. Interestingly, a century ago, PFD was rather considered a hysterical syndrome expressing an unresolved psychological conflict.[6,7] Recent findings that disturbances within striato-thalamo-cortical circuits may play a role not only in dystonia but also in hysterical sensorimotor loss,[7] render strict classifications of symptoms as either neurological or psychiatric/psychological questionable.

The aim of the present study was to further disentangle the complex phenotypic spectrum of psychiatric/psychological characteristics in PFD patients. Apart from defining psychiatric diagnoses, we were specifically interested in prevalence rates of personality disorders which are defined as an enduring inflexible pattern of inner experience and behaviour starting in early adulthood and leading to clinically significant distress or impairment. Furthermore, we aimed to unravel specific personality traits according to the descriptive five factors personality model developed from empirical research.[8] A priori, we expected increased prevalence rates of affective and anxiety spectrum disorders including anxious-avoidant personality disorders (cluster C) in PFD patients compared to the general population. We further hypothesized that these usually manifest prior to the neurological symptoms. 


\section{Methods:}

Patients

Eighty-six adult PFD patients (>18 years) were consecutively recruited from two dystonia outpatient clinics of University Hospitals in Northern Germany. Refusal rate was about $20 \%$. Patients with clinical evidence for secondary dystonia were excluded. The study was approved by the local ethics committees and written informed consent was obtained from all participating subjects in accordance with the Declaration of Helsinki.

Neurological examination was carried out by three experienced movement disorder specialists (JH, TB, AM). Age of onset for dystonia was determined as the time of first symptoms, e.g. either dystonia or tremor (table 1 and supplemental material). All patients were tested negative for the GAG deletion in the DYT1 gene.

\section{Psychiatric/psychological assessment}

Psychiatric (axis I) and personality (axis II) disorders according to the DSM-IV criteria,[9] were established by two specially trained psychiatrists (H.R, JS) using all available clinical data including responses on the Structured Clinical Interview for DSM-IV (SCID).[10] Diagnoses were to be agreed upon independently by two additional experienced psychiatrists (SS, RL). For diagnosis of secondary social phobia, DSM diagnostic criteria A-G had undoubtedly to be fulfilled, thereby clearly distinguishing social phobia from embarrassment due to dystonia symptoms.[11] Whenever possible, the five-factor inventory (NEO-FFI)[12] was applied to assess the value of replicable personality traits such as neuroticism, extraversion, openness, agreeableness and conscientiousness complementary to DSM-IV personality disorders. Mean scores obtained with the NEO-FFI were compared to standardized 
means [12] by computing effect size estimates of key measures as a descriptive approach using Cohen's d procedure.[13]

\section{Statistical analysis}

Prevalence rates of DSM-IV axis I disorders in the PFD sample were compared by logistic regression analysis to those of a representative sample consisting of 3,943 individuals between 18-64 years randomly drawn from registration office files of the general population in Northern Germany.[14] Comparable to the SCID, the control sample was evaluated by a personal interview for establishing all relevant psychiatric axis I diagnosis according to the DSM-IV, i.e. the "Munich Composite International Diagnostic Interview" (M-CIDI).[15] Clinical reappraisal studies have shown that CIDISCID agreement in DSM-IV diagnoses is generally good.[16] To adapt both samples, only PFD patients younger than 65 years $(\mathrm{N}=57)$ were included. Sex and age were implemented as independent variables, and each of the psychiatric disorders as dependent variables to calculate odds ratios with $95 \%$ confidence intervals. We used the Breslow-Day Test to test for homogeneity of odds ratios.[17] The prevalence rates for personality disorders were compared by Chi-square tests to those of a population-based random sample based on 2,053 subjects $(1,142$ men, 911 women) from Northern Europe (18-64 years) selected for the evaluation of DSMIV personality disorders.[18] 
Table 1: Psychiatric features in PFD patients compared to a population-based sample [14]

\begin{tabular}{|c|c|c|c|c|c|c|c|c|}
\hline & \multicolumn{2}{|c|}{$\begin{array}{l}\text { Mean Age Of Onset, } \\
\text { Years (SD) }\end{array}$} & \multicolumn{3}{|c|}{ Prevalence In PFD Sample, N (\%) } & \multicolumn{3}{|c|}{$\begin{array}{l}\text { Prevalence In Population-based } \\
\text { Sample, N (\%) }\end{array}$} \\
\hline & $\begin{array}{l}\text { Psychiatric } \\
\text { Disorder }\end{array}$ & $\begin{array}{l}\text { PFD } \\
\text { Symptoms }\end{array}$ & $\begin{array}{c}\text { Total } \\
(\mathrm{N}=86)\end{array}$ & $\begin{array}{l}\text { Women } \\
(\mathrm{N}=63)\end{array}$ & $\begin{array}{c}\text { Men } \\
(N=23)\end{array}$ & $\begin{array}{c}\text { Total } \\
(\mathrm{N}=3943)\end{array}$ & $\begin{array}{l}\text { Women } \\
(\mathrm{N}=1942)\end{array}$ & $\begin{array}{c}\text { Men } \\
(\mathrm{N}=2001)\end{array}$ \\
\hline Axis I & $24.3(11.4)$ & $42.5(14.4)$ & $53(61.6)$ & $35(55.6)$ & $18(78.32)$ & $1383(35.1)$ & $782(40.3)$ & $601(30.2)$ \\
\hline Axis II & $18^{\star * \star}$ & $43.9(15.6)$ & $33(38.4)$ & $24(38.1)$ & $9(39.1)$ & * & * & * \\
\hline Anxiety** & $22.9(11.2)$ & $40.6(16.5)$ & $32(37.2)$ & $23(36.5)$ & $9(39.1)$ & $586(14.9)$ & $397(20.4)$ & $189(9.4)$ \\
\hline Social Phobia & $23.8(13.2)$ & $40.9(15.8)$ & $20(23.3)$ & $14(22.2)$ & $6(26.1)$ & $72(1.8)$ & $45(2.3)$ & $27(1.3)$ \\
\hline Specific Phobia & $18^{\star \star \star}$ & $35.7(14.5)$ & $14(16.3)$ & $9(14.3)$ & $5(21.7)$ & $411(10.4)$ & $280(14.4)$ & $131(6.5)$ \\
\hline Agoraphobic Disorder & $23.3(9.8)$ & $36.0(17.7)$ & $9(10.5)$ & $7(11.1)$ & $2(8.7)$ & $41(1.0)$ & $28(1.4)$ & $13(0.6)$ \\
\hline Panic Disorder & $17.9(0.4)$ & $38.7(14.0)$ & $7(8.1)$ & $6(9.5)$ & $1(4.3)$ & $36(0.9)$ & $23(1.2)$ & $13(0.6)$ \\
\hline Generalized Anxiety Disorder & $25.3(12.7)$ & $40.7(27.5)$ & $3(3.5)$ & $3(4.8)$ & $0(0.0)$ & $29(0.7)$ & $18(0.9)$ & $11(0.5)$ \\
\hline Obsessive-Compulsive Disorder & $18^{\star * \star}$ & $31.0(14.1)$ & $2(2.3)$ & $2(3.2)$ & $0(0.0)$ & $20(0.5)$ & $17(0.9)$ & $3(0.1)$ \\
\hline
\end{tabular}


Table 1 (continued 1): Psychiatric features in PFD patients compared to a population-based sample [14]

\begin{tabular}{|c|c|c|c|c|c|c|c|c|}
\hline & \multicolumn{2}{|c|}{$\begin{array}{c}\text { Mean Age Of Onset, } \\
\text { Years (SD) }\end{array}$} & \multicolumn{3}{|c|}{ Prevalence In PFD Sample, N (\%) } & \multicolumn{3}{|c|}{$\begin{array}{l}\text { Prevalence In Population-based } \\
\text { Sample, N (\%) }\end{array}$} \\
\hline & $\begin{array}{l}\text { Psychiatric } \\
\text { Disorder }\end{array}$ & $\begin{array}{c}\text { PFD } \\
\text { Symptoms }\end{array}$ & $\begin{array}{c}\text { Total } \\
(\mathrm{N}=86)\end{array}$ & $\begin{array}{l}\text { Women } \\
(N=63)\end{array}$ & $\begin{array}{c}\text { Men } \\
(N=23)\end{array}$ & $\begin{array}{c}\text { Total } \\
(\mathrm{N}=3943)\end{array}$ & $\begin{array}{l}\text { Women } \\
(\mathrm{N}=1942)\end{array}$ & $\begin{array}{c}\text { Men } \\
(\mathrm{N}=2001)\end{array}$ \\
\hline Major Depression & $21.8(8.5)$ & $42.4(16.5)$ & $23(26.7)$ & $19(30.2)$ & $4(17.4)$ & $446(11.3)$ & $308(15.9)$ & $138(6.9)$ \\
\hline Dysthymic Disorder & $18^{* * *}$ & $27.7(13.1)$ & $6(7.0)$ & $4(6.3)$ & $2(8.7)$ & $94(2.4)$ & $62(3.2)$ & $32(1.6)$ \\
\hline Alcohol Abuse & $20.3(4.9)$ & $40.2(15.2)$ & $13(15.1)$ & $6(9.5)$ & $7(30.4)$ & $178(4.5)$ & $20(1.0)$ & $158(7.9)$ \\
\hline Alcohol Dependance & $25.0(12.1)$ & $36.7(7.6)$ & $4(4.7)$ & $1(1.6)$ & $3(13.0)$ & $149(3.8)$ & $29(1.5)$ & $120(6.0)$ \\
\hline Drug Abuse & $19.5(2.1)$ & $35.0(7.1)$ & $2(2.3)$ & $0(0.0)$ & $2(8.7)$ & $30(0.8)$ & $9(0.5)$ & $21(1.0)$ \\
\hline Drug Dependance & $22.0(5.7)$ & $40.5(30.4)$ & $2(2.3)$ & $0(0.0)$ & $2(8.7)$ & $14(0.4)$ & $6(0.3)$ & $8(0.4)$ \\
\hline Bulimia Nervosa & 18 & 13 & $1(1.2)$ & $1(1.6)$ & $0(0.0)$ & $2(0.1)$ & $2(0.1)$ & $0(0.0)$ \\
\hline Posttraumatic Stress Disorder & 18 & 57 & $1(1.2)$ & $1(1.6)$ & $0(0.0)$ & $54(1.4)$ & $42(2.2)$ & $12(0.6)$ \\
\hline
\end{tabular}

${ }^{*}$ no data available

** number of individuals with any anxiety disorder (some having more than one)

${ }^{* \star *}$ participants reported that the referring disorder was present from early adulthood 


\section{Results:}

Clinical characterization

Within the group of 86 PFD patients, there was a greater proportion of women (73.3\%) who were older (mean 57.9 vs. 50.0 years, $p=0.03$ ). Cervical dystonia was the most frequent PFD form (81.4\%). The 16 patients with blepharospasm were older (mean 64.6 vs. 53.8 years, $p=0.002$ ) and had a higher age of onset (mean 54.9 vs. 43.8 years, $p=0.005$ ) than patients with cervical dystonia. Blepharospasm was more common in women $(23.8 \%)$ than in men (4.3\%; supplemental material, table 1$)$.

\section{Psychiatric and personality disorders}

Lifetime prevalence for any psychiatric or personality disorder was $70.9 \%$ (table 1). Prevalence rates of lifetime psychiatric and personality disorders did not differ between the subgroups with cervical dystonia and blepharospasm.

Compared to the population-based sample, PFD patients had a 4.5-fold increased chance for any psychiatric disorder including 25 patients with two or more psychiatric disorders. Highest chances were found for social phobia (OR 21.6, C.I. 11.1-41.9), followed by agoraphobia (OR 16.7, C.I. 7.4-37.3) and panic disorder (OR 11.5, C.I. 4.5-29.2), obsessive-compulsive disorder (OR 8.4, C.I. 1.7-38.9), alcohol abuse (OR 9.6, C.I. 4.5-20.3) and drug dependence (OR 14.9, C.I. 3.1-70.7). Chances for mood disorders were only moderately increased (OR 3.0, C.I. 1.7-5.5 for major depression; supplementary material, table 2). Most of the psychiatric disorders, except for social phobia, were present prior to the manifestation of dystonia symptoms (table 1). With respect to personality disorders, increased rates compared to the population-based sample were found for cluster C disorders (32.6\%) including obsessive-compulsive (22.1\%) and avoidant personality disorders (16.3\%; supplemental material, table 3). 
NEO-FFI personality factors

Fifty-six of the 86 PFD patients also completed the NEO-FFI (figure 1 and supplemental material, table 4). These patients did not differ in terms of prevalence of psychiatric disorders or demographic and clinical features from the noncompleters. Generally, neuroticism scores were higher in PFD patients affected with either psychiatric or personality disorders than in unaffected patients (supplemental material, table 5). Mean openness scores in patients were decreased compared to standardized means,[12] reflecting a more conventional behaviour, conservative ideas and the preference of approved settings, with subdued emotional reactions. Agreeableness scores were increased in both PFD women and men indicating a pronounced tendency to be compassionate and cooperative. For conscientiousness, increased scores were observed without gender difference, pointing obsessive orderliness and perfectionism. Decreased neuroticism scores in PFD women indicated reduced emotional reactivity, whereas PFD men scored lower on extraversion compared to the standardized group, characterizing them as more introverted and autonomous.

(Figure 1 about here)

\section{Discussion}

Distinct neuropsychiatric and personality profiles in PFD

Based on a typical PFD population,[19] we confirmed previous reports on increased chances for psychiatric disorders in PFD patients, ranging from an odds ration of 3.0 for major depression to 21.6 for secondary social phobia. More importantly, our findings of increased rates of anxious personality disorders (cluster $\mathrm{C}$ ) considerably expand such reports,[1-4] implying that there is a continuum from distinct personality traits and certain personality disorder clusters to the manifestation of mainly anxiety 
disorders in PFD patients. From the personality trait perspective, PFD patients were characterized by a preference of approved settings and obsessive characteristics on the one hand and the tendency to compromise one's interests with others but to avoid conflicts on the other. Correspondingly, more detailed analyses showed that higher neuroticism scores were especially found in PFD patients diagnosed with a psychiatric or personality disorder.

Although all patients were successfully treated with botulinum toxin, the chance to develop secondary social phobia was extremely high. Social phobia has been shown to be even more common in PFD than in other possibly stigmatizing disorders such as alopecia areata, thus unlikely being a mere consequence of disfigurement.[2] Development of secondary social phobia may have been facilitated by the pronounced personality traits revealed by the NEO-FFI, implying that PFD patients have difficulties in coping with dystonia symptoms and thus avoid social situations and being evaluated by others.

Increased chances for alcohol abuse and drug dependence in men may be a consequence of the fact that motor symptoms in dystonia are often relieved by alcohol, benzodiazepine or anticholinergic drugs.[20] Interestingly, results from genetic studies suggest that there may be an additional neurobiological factor predisposing to substance-related disorders in PFD.[21,22]

Neurobiological basis for motor and psychiatric symptoms in PFD A dysfunction of basal ganglia-thalamo-cortical circuits has been assumed to underlie both motor and psychiatric symptoms.[7] The link between networks subserving mental and motor functions may be provided by direct affective input to the caudate nucleus and the thalamus originating from the amygdale and the orbitofrontal 
cortex.[23] It is conceivable that in a disorder such as PFD, disturbed neural activity in motor loops linking the basal ganglia via the thalamus to the frontal cortex may also have an influence on the so-called limbic loops which mediate attentional, cognitive and limbic functions resulting in both altered motor and affective processing.[24]

Genetic factors may be another shared neurobiological basis. There is a range of inherited movement disorders where psychiatric disorders are part of the phenotypic spectrum of the genetic mutation.[25] In myoclonus-dystonia, higher rates of obsessive-compulsive disorder and alcohol dependence were found in SGCE mutation carriers. $[21,22]$ This example illustrates that psychiatric disorders may be linked to the same genetic abnormality that is associated with a distinct movement disorder.

\section{Limitations}

We cannot exclude a selection bias due to the fact that only PFD patients agreeing to botulinum toxin treatment were recruited and that they may have scored higher on agreeableness than those who refused, which is a general limitation of clinical studies. Based on the assumption that different dystonia subtypes share common aetiological factors,[26] we did not intend to make any statement with respect to specific neuropsychiatric features of specific PFD subgroups or differences between PFD subgroups. In fact, a high phenotypic variability has been observed even within families with multiples cases of dystonia. Further studies with larger sample sizes of subgroups may be able to answer this question.

In conclusion, the results of the present study expand earlier findings showing more specifically that anxiety spectrum disorders represent part of the phenotypic PFD 
spectrum. Interdisciplinary research effort is needed to unravel the shared disease mechanisms of both motor and neuropsychiatric symptoms in PFD with highresolution imaging and genetic approaches being most promising. Distinct symptoms may be associated with specific alterations of limbic and frontal circuitry.[27] 


\section{Reference:}

1. Guendel H, Wolf A, Xidara V, et al. High psychiatric comorbidity in spasmodic torticollis: a controlled study. J Nerv Ment Dis 2003;191:465-473.

2. Guendel $H$, Wolf $A$, Xidara $V$, et al. Social phobia in spasmodic torticollis. $J$ Neurol Neurosurg Psychiatry 2001;71:499-504.

3. Duane DD, Vermilion KJ. Cognition and affect in patients with cervical dystonia with and without tremor. Adv Neurol 2004;94:179-189.

4. Cavallaro R, Galardi G, Cavallini MC, et al. Obsessive compulsive disorder among idiopathic focal dystonia patients: an epidemiological and family study. Biol Psychiatry 2002;52:356-361.

5. Cleveland SE. Personality dynamics in torticollis. J Nerv Ment Dis 1959;129:150-161.

6. Choppy-Jacolin M, Ferrey G, Demaria C. A psychometric study of 34 patients afflicted with spasmodic torticollis. Acta Neurol Scand 1977;55:483-492.

7. Vuilleumier $\mathrm{P}$, Chicherio $\mathrm{C}$, Assal F, et al. Functional neuroanatomical correlates of hysterical sensorimotor loss. Brain 2001;124:1077-1090.

8. Goldberg LR. The structure of phenotypic personality traits. Am Psychol 1993;48:26-34

9. Sass H, Wittchen HU, Zaudig M. Diagnostisches und Statistisches Manual Psychischer Stoerungen - Textrevision - DSM-IV-TR. Goettingen: HogrefeVerlag; 2003

10. Wittchen HU, Zaudig M, Fydrich T. Strukturiertes Klinisches Interview fuer DSM-IV. Goettingen: Hogrefe-Verlag; 1997.

11. Oberlander EL, Schneier FR, Liebowitz MR. Physical disability and social phobia. J Clin Psychopharmacol 1994;14:136-143.

12. Borkenau P, Ostendorf F. NEO-Fuenf-Faktoren Inventar (NEO-FFI) In: Costa 
and McCrae. Goettingen, Bern, Toronto, Seattle: Hogrefe Verlag fuer Psychologie; 1993.

13. Cohen J. Statistical power analysis for the behavioral sciences. Hillsdale: Lawrence Earlbaum Associates; 1988.

14. Meyer C, Rumpf HJ, Hapke U, et al. Prevalence of alcohol consumtion, abuse and dependence in a country with high per capita consumption: findings from the German TACOS study. Soc Psychiatry Psychiatr Epidemiol 2000;35:539547.

15. Wittchen HU, Beloch E, Garczynski E, et al. Muenchener Composite International Diagnostic Interview (M-CIDI), Version 2.2. Muenchen: MaxPlanck-Institut fuer Psychiatrie; 1995.

16. Haro JM, Arbabzadeh-Bouchez S, Brugha TS, et al. Concordance of the Composite International Diagnostic Interview Version 3.0 (CIDI 3.0) with standardized clinical assessments in the WHO World Mental Health surveys. Int J Methods Psychiatr Res 2006;15:167-80.

17. Breslow NE, Day NE, ed. Statistical Methods in Cancer Research, Vol 1. The Analysis of Case-Control Studies. Lyon: IARC;1980.

18. Torgersen S, Kringlen E, Cramer V. The Prevalence of Personality Disorders in a Community Sample. Arch Gen Psychiatry 2001;58:590-596.

19. Klein C, Ozelius LJ. Dystonia. Clinical features, genetics, and treatment. Curr Opin Neurol 2002;15:491-497.

20. Greene P, Shale S, Fahn S. Analysis of open label trials in torsion dystonia using high dosages of anticholinergics and other drugs. Mov Disord 1988;3:46-60.

21. Saunders-Pullman R, Shriberg J, Heimann G, et al. Myoclonus dystonia: Possible association with obsessive-compulsive disorder and alcohol 
dependence. Neurology 2002;58:242-245.

22. Hess CW, Raymond D, de Carvalho Aguiar P, et al. Myoclonus-dystonia, obsessive-compulsive disorder, and alcohol dependence in SGCE mutation carriers. Neurology 2007;68:522-524.

23. Ron M. Explaining the unexplained: Understanding hysteria. Brain 2001;124:1065-1066.

24. Alexander GE, Crutcher MD, DeLong MR. Basal gangliathalamocortical circuits: Parallel substrates for motor, oculomotor,"prefrontal" and "limbic" functions. Prog Brain Res 1990;85:119-146.

25. Steinlechner S, Stahlberg J, Voelkel B, et al. Co-occurrence of affective and schizophrenia spectrum disorders with PINK1 mutations. J Neurol Neurosurg Psychiatry 2007;78:532-535.

26. Defazio G, Berardelli A, Hallett M: Do primary adult-onset focal dystonias share aetiological factors? Brain 2007;130:1183-1193.

27. Reetz K, Lencer R, Steinlechner S, et al: Limbic and Frontal Cortical Degeneration Is Associated with Psychiatric Symptoms in PINK1 Mutation Carriers. Biol Psychiatry 2008;64:241-247. 


\section{Legend}

Figure 1: Comparison of mean NEO-FFI scores in PFD patients with standardized means

* Medium effect size of $\geq 0.5$ and $<0.8$ according to Cohen [13]

** Large effect size of $\geq 0.8$ according to Cohen [13] 


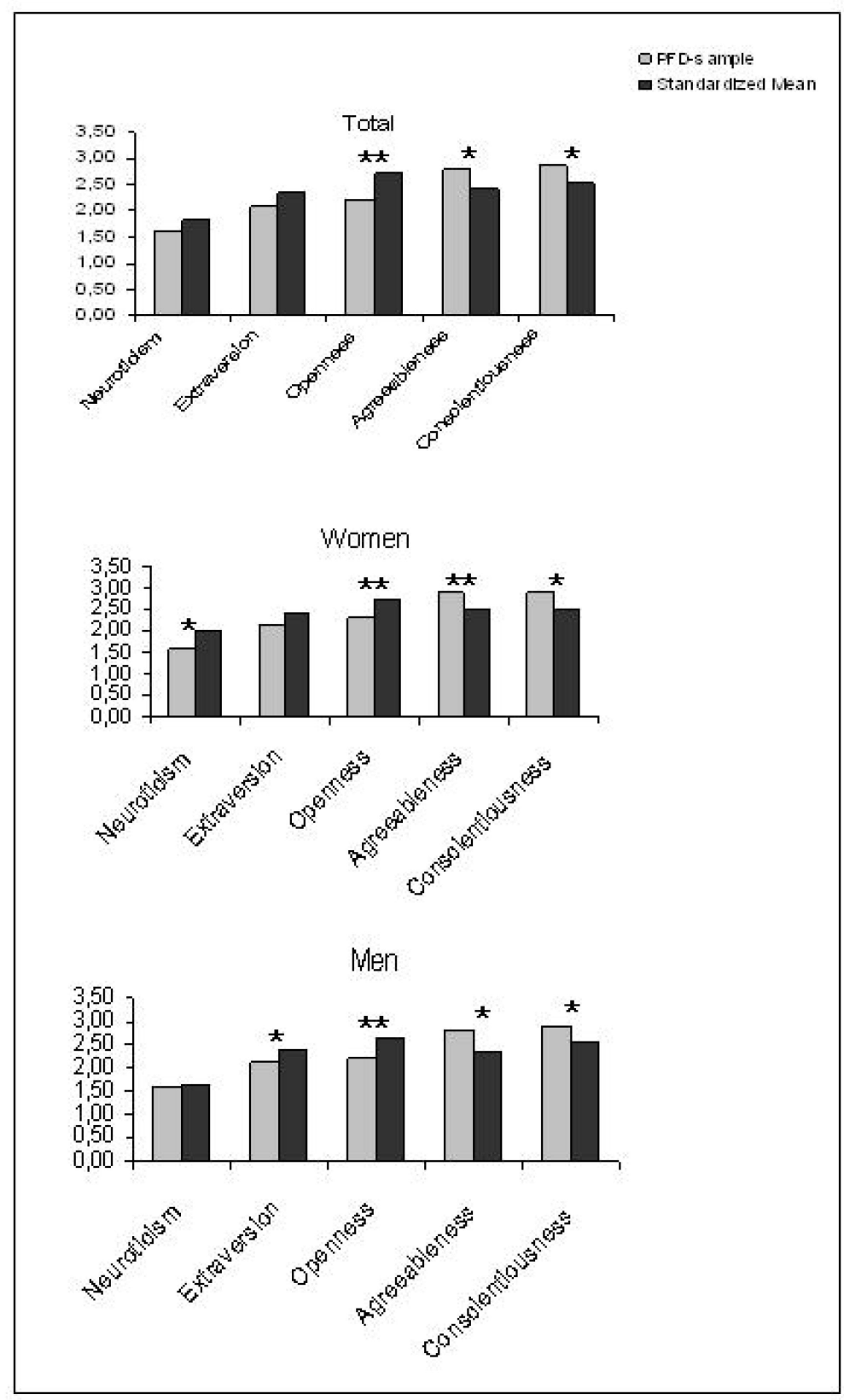

